\title{
Emergência de plântulas de porta-enxertos de pessegueiro submetidos a diferentes períodos de estratificação ${ }^{1}$
}

\author{
Emergence of seedlings of rootstock of the peach when submitted to different periods \\ of stratification
}

\author{
Doralice Lobato de Oliveira Fischer ${ }^{2}$, Márcia Denise Rossarolla ${ }^{3}$, Claudiomar Fischer ${ }^{4}$, Elaine Lobato de \\ Oliveira $^{4}$ e Clevison Luiz Giacobbo ${ }^{5 *}$
}

\begin{abstract}
RESUMO - Objetivou-se com este trabalho, avaliar a germinação e o desenvolvimento de plantas oriundas de duas cultivares de pessegueiro 'Capdeboscq' e 'Okinawa' sob diferentes períodos de armazenamento, em viveiro comercial da empresa Frutplan Mudas Ltda, em Pelotas - RS, no período de maio a dezembro de 2009. Os caroços das duas cultivares foram armazenados em embalagens de papel por um período de 120 dias, sendo realizados os seguintes procedimentos: 10 dias de temperatura ambiente +110 dias de frio; 40 dias de temperatura ambiente +80 dias de frio; 70 dias de temperatura ambiente +50 dias de frio; 100 dias de temperatura ambiente +20 dias de frio e 120 dias de temperatura ambiente. Utilizando câmara fria programada para $6 \pm 2{ }^{\circ} \mathrm{C}$. $\mathrm{O}$ experimento foi conduzido em blocos casualizados, com quatro repetições e 25 sementes por parcela, no arranjo fatorial 2x5 (duas cultivares e cinco períodos de estratificação). As variáveis analisadas foram: porcentagem de plântulas emergidas, altura das plantas, diâmetro do tronco medido a $10 \mathrm{~cm}$ do colo, índice de velocidade de emergência em campo (IVEC) e dias para obtenção de $70 \%$ de emergência. A emergência da cv. Okinawa foi próximo a zero, com isto não foi considerada para avaliação de plântulas. Para a cv. Capdeboscq verificou-se diferenças significativas apenas para a variável dias para obtenção de 70\% de emergência de plântulas, 112 a 123 dias, exceto para o tratamento com maior horas de frio que não atingiu os $70 \%$ de emergência. Conclui-se que os períodos de estratificação e frio não se mostraram vantajosos para obtenção de porta-enxertos de pessegueiro destas cultivares nas condições em que foi conduzido o experimento.
\end{abstract}

Palavras-chave: Pessegueiro. Armazenamento. Germinação.

ABSTRACT - The objective of this study was to evaluate the germination and development of plants from two cultivars of the peach, 'Capdeboscq' and 'Okinawa', for different periods of storage, at the commercial nursery of the company Frutplan Mudas Ltda., in Pelotas, Rio Grande do Sul, from May to December of 2009. The kernels of both cultivars were stored in paper wrappings for a period of 120 days, with the following procedures being carried out: 10 days at room temperature +110 days of low temperature, 40 days at room temperature +80 days of low temperature, 70 days at room temperature +50 days of low temperature, 100 days at room temperature +20 days of low temperature, and 120 days at room temperature, using a cold room programmed for $6 \pm 2{ }^{\circ} \mathrm{C}$. The experiment was carried out in a randomized block design, with four replications and 25 seeds per plot, in a $5 \times 2$ factorial layout (two cultivars and five periods of stratification). The variables analyzed were: the percentage of seedling emergence; plant height; trunk diameter measured at $10 \mathrm{~cm}$ from the soil, speed of emergence in the field (SEF) and days taken to reach $70 \%$ emergence. The emergence of cv. Okinawa was close to zero and therefore it was not considered when evaluating the seedlings. For the cv. Capdeboscq, significant differences were found only for the variable of days taken to achieve $70 \%$ seedling-emergence, 112 to 123 days, except for that treatment with the greatest time at low-temperatures, which did not reach $70 \%$ emergence. It is concluded that periods of stratification and low temperatures offer no advantage to obtaining rootstocks of these peach cultivars, for the conditions under which the experiment was carried out.

Key words: Peach tree. Storage. Germination.

\footnotetext{
*Autor para correspondência

'Recebido para publicação em 13/09/2011; aprovado em 08/08/2012

Pesquisa financiada na forma de bolsa pelo CNPq

${ }^{2}$ Área de fruticultura e propagação de plantas, Instituto Federal de Educação, Ciência e Tecnologia Sul-Rio-Grandense, Campus Visconde da Graça, Pelotas-RS, Brasil, doralicefischer@ cavg.ifsul.edu.br

${ }^{3}$ Curso de agronomia, UNIPAMPA, Campus Itaqui, Itaqui-RS, Brasil, mdrossarolla@gmail.com

${ }^{4}$ Frutplan Mudas Ltda, Caixa Postal 623, Pelotas-RS, Brasil, fischer@ frutplan.com.br, frutplan@ frutplan.com.br

${ }^{5}$ Curso de Agronomia. Área de fruticultura e propagação de plantas, Universidade Federal da Fronteira Sul/UFFS, Campus Chapecó, Acesso Canários da Terra, S/N, Bairro Seminário - UFFS, Chapecó-SC, Brasil, 89813-140, clevison.giacobbo@uffs.edu.br
} 


\section{INTRODUÇÃO}

Entre as frutíferas de caroço, o pêssego se destaca no mundo inteiro, tanto pelo sabor quanto pela aparência. Por ser uma fruta muito apreciada, consumida ao natural ou processada na forma de doces e compotas, houve considerada expansão da produção (FOOD AND AGRICULTURAL ORGANIZATION, 2012).

Apesar da elevação dos rendimentos médios por unidade de área, propiciada pelo melhoramento genético, a persicultura brasileira ainda necessita de novas tecnologias que contribuam para o aumento da produtividade (MAYER; PEREIRA, 2008). Desta forma a qualidade da muda a ser utilizada é de fundamental importância para o sucesso da atividade frutícola, sendo o tempo de formação das mudas um fator relevante para os viveiristas (HOFFMANN; FACHINELLO; NACHTIGAL, 2005; REIS; CHALFUN; REIS, 2010).

As mudas de porta-enxertos de pessegueiro podem ser obtidas através dos métodos de propagação sexuada ou assexuada, sendo a via sexuada, ainda, a mais utilizada (MAYER et al., 2007). Segundo Hoffman, Fachinello e Nachtigal (2005) a propagação por sementes é um método eficiente para produzir plantas livres de doenças. Embora tenha a desvantagem de ocorrer variabilidade genética, esse método de propagação apresenta vantagens como maior longevidade, desenvolvimento vigoroso e sistema radicular vigoroso e profundo.

Para que as sementes das espécies frutíferas de clima temperado germinem é necessário que passem por um período de estratificação sob frio úmido. Esta necessidade é variável de espécie para espécie e também entre cultivares (dormência fisiológica). No caso do pessegueiro, para se obter mudas de qualidade, torna-se necessária a estratificação das sementes (caroços e/ou amêndoas) em substrato umedecido sob condições de ambiente frio $\left(5\right.$ a $\left.12{ }^{\circ} \mathrm{C}\right)$ por algumas semanas, antes da sua semeadura (HOFFMANN; NACHTIGAL; BERNARDI, 2003). A manutenção das sementes em ambiente úmido e frio estimula a diminuição dos teores de inibidores e favorece a síntese de promotores da germinação (RAMOS et al., 2002).

Nos viveiros, produtores de mudas de pessegueiro, as sementes são, normalmente, colocadas sob estratificação, por 45-60 dias, ou por maiores períodos, desconhecendo-se, no entanto, a quantidade de frio necessário para a completa superação da dormência.

Devido à amplitude temporal/térmica das condições ambientais e do potencial de germinação das sementes de porta-enxerto de pessegueiro, que pode variar em função da cultivar, objetivou-se avaliar a germinação e o desenvolvimento das plantas oriundas das cultivares
Capdeboscq e Okinawa, sob diferentes períodos de armazenamentos em câmara fria.

\section{MATERIAL E MÉTODOS}

Este trabalho foi conduzido em campo, na empresa Frutplan Mudas Ltda, Pelotas, RS, no período de maio a dezembro de 2009. O material propagativo constituiu-se de caroços oriundos de plantas matrizes das cultivares Capdeboscq e Okinawa, obtidos no Banco de Germoplasma do viveiro da empresa.

Os caroços das duas cultivares foram armazenados em embalagens de papel (cor parda) por um período de 120 dias, sendo realizados os seguintes procedimentos: 10 dias de temperatura ambiente +110 dias de frio; 40 dias de temperatura ambiente +80 dias de frio; 70 dias de temperatura ambiente +50 dias de frio; 100 dias de temperatura ambiente +20 dias de frio e 120 dias de temperatura ambiente $(2.640 ; 1.920$; $1.200 ; 480$ e $0 \mathrm{~h}$ de frio, respectivamente). Utilizando câmara fria programada para $6 \pm 2{ }^{\circ} \mathrm{C}$ e umidade relativa do ar da câmara de $90 \pm 2 \%$.

O experimento foi conduzido em blocos casualizados, com quatro repetições e 25 sementes por parcela, no arranjo fatorial 2 × 5 (duas cultivares e cinco períodos de estratificação).

Os caroços, provenientes de frutos maduros obtidos de polinização livre, logo após a colheita, foram submetidos ao despolpamento e lavados em água corrente. Em seguida foram imersos em uma solução de hipoclorito de sódio (2,5\%) e água na proporção de 1:2, por um período de 10 minutos, depois foram lavados em água corrente e colocados para secar a sombra.

Após a estratificação, os lotes de sementes foram retirados do frio e juntamente com o tratamento de 120 dias (sem frio) foram semeados a campo, sem o rompimento prévio do endocarpo.

A semeadura foi realizada no dia 23 de maio a 2,5 $\mathrm{cm}$ de profundidade, com espaçamento de $5 \mathrm{~cm}$ entre caroços e 1,0 m entre filas (linhas), em solo franco arenoso raso, previamente preparado, com $\mathrm{pH}$ corrigido para 6,0 e com adubação de pré-plantio de fósforo e potássio (250 de super triplo ha-1 $+100 \mathrm{~kg} \mathrm{ha}^{-1} \mathrm{de} \mathrm{KCl}$ ), conforme análise do solo.

Realizou-se três adubações de cobertura, a primeira quando as plântulas estavam com altura entre 7 a $10 \mathrm{~cm}$, utilizando-se sulfato de amônia na dosagem de $200 \mathrm{~kg} \mathrm{ha}^{-1}$. Após 45 dias da primeira aplicação, realizou-se uma nova adubação utilizando NPK na formulação 13-13-13 (250 $\left.\mathrm{kg} \mathrm{ha}^{-1}\right)$ e a terceira adubação 
foi realizada, novamente, com sulfato de amônia (de $200 \mathrm{~kg} \mathrm{ha}^{-1}$ ), trinta dias após a segunda.

A disponibilidade hídrica foi monitorada diariamente e quando necessária realizou-se a irrigação da área de plantio através da aspersão.

As variáveis analisadas foram: porcentagem de plântulas emergidas, altura das plantas, diâmetro do tronco a $10 \mathrm{~cm}$ do colo, índice de velocidade de emergência em campo (IVEC), para a qual foram avaliadas, a cada sete dias, a germinação a campo e dias para obtenção de $70 \%$ de emergência. Os dados foram avaliados no mês de dezembro, antes do período de enxertia.

Os dados foram submetidos à análise da variância pelo teste $\mathrm{F}$ e, quando significativos, comparadas às médias pelo teste de Duncan a $5 \%$ de significância. Os dados expressos em porcentagem (emergência) foram transformados em arco seno da raiz de $\mathrm{x} / 100$. O programa estatístico WinStat, versão 2.0 (MACHADO; CONCEIÇÃO, 2003), foi utilizado para as análises.

\section{RESULTADOS E DISCUSSÃO}

Nas condições em que foi conduzido o experimento, observou-se que a cultivar Okinawa não expressou seu potencial germinativo, apresentando emergência próxima a $0 \%$. Ghayyad, Kunbysa e Napolsy (2010), em trabalho com Prunus mahaleb, verificaram resultados, próximo a $0 \%$, semelhantes ao encontrado neste trabalho, quando mantiveram o endocarpo nas sementes, mesmo com aplicação de hormônio para a germinação e estratificação. Entretanto, em trabalho com a mesma cultivar deste 'Okinawa', Reis, Chalfun e Reis (2010) ao testarem a emergência das amêndoas de 'Okinawa', submetida a quatro períodos de estratificação, três condições de ambientes, na presença e ausência de giberelina, obtiveram percentuais superiores ao encontrado neste trabalho, variando de 10,50 a $87 \%$ de germinação.

No presente trabalho, durante o período de armazenamento, os caroços foram mantidos secos em embalagens de papel pardo, somente com a temperatura ambiente da câmara fria. Essa condição pode ter proporcionado a perda de umidade natural das sementes, interferindo no processo necessário para completar a maturação do embrião. O que pode explicar o fato da emergência ter ocorrido somente na cultivar Capdeboscq, possivelmente por esta ser uma cultivar de maturação tardia, pois segundo Fachinello et al. (2005), cultivares precoces de pessegueiro, onde o embrião pode não estar completamente desenvolvido, no momento da maturação do fruto, muitas vezes é necessário cultivar o embrião em meio de cultura adequado, para completar seu desenvolvimento. De acordo com Pereira, Nachtigal e Roberto (2002) a obtenção dos porta-enxertos de 'Okinawa' por semente, exige alguns cuidados, entre estes, submeter as sementes a estratificação por um período mínimo de 45 dias, necessária para que ocorra a maturação do embrião por se tratar de uma cultivar de maturação precoce. $\mathrm{O}$ armazenamento pode ser feito na forma de amêndoas acondionadas em um recipiente que mantenha um elevado teor de umidade ou na forma de caroços acondicionados em sacos plásticos fechados.

Entretanto, considerando a afirmação de Finardi (1998) em que a vernalização pode ser realizada de maneira natural no campo, desde que o plantio seja realizado de abril a maio, o período de estratificação sob frio úmido pode ter ocorrido naturalmente após o plantio. Com isto, a falta de germinação para cultivar Okinawa, pode estar atrelada ainda somente a presença do endocarpo que não rompeu para que a semente emergisse, conforme observado nas linhas de plantio. Para Hoffmann, Nachtigal e Bernardi, (2003) no caso do pessegueiro, além da dormência fisiológica, as sementes apresentam dormência física, devido à presença do envoltório duro e impermeável.

Para a cultivar Capdeboscq, os caroços armazenados e semeados a campo apresentaram índices de emergência semelhantes, independente do tempo de submissão ao frio ou na ausência de baixas temperaturas. Verificou-se diferenças significativas somente para a variável altura de plantas, no qual as plantas do tratamento com 100 dias de armazenamento (480 $\mathrm{h}$ de frio) estavam maiores que as dos tratamentos 10 dias e 70 dias de armazenamento (2.640 e $1.200 \mathrm{~h}$ de frio, respectivamente). Para as demais variáveis as médias observadas foram: $72,8 \%$ para a porcentagem de plântulas emergidas, $6,7 \mathrm{~mm}$ de diâmetro do tronco e 14,1 de IVEC (Tabela 1).

Neste trabalho foram verificados resultados semelhantes aos verificados por Fischer et al. (2010) em trabalhos sobre período de estratificação na germinação de sementes de mirtileiro, os quais verificaram que o tempo de estratificação não foi um fator condicionante na emergência, porém verificaram para a cultura, um maior percentual de plantas mortas na pós-emergência quando não estratificado.

O percentual encontrado neste trabalho está próximo ao encontrado por Wagner Júnior et al. (2008a) em trabalho com 120 dias a frio de $5^{\circ} \mathrm{C}$, sobre período de estratificação e desenvolvimento inicial de Seedlings de pessegueiro ( $80 \%$ de germinação). 
Tabela 1 - Porcentagem de plântulas emergidas, altura das plantas, diâmetro do tronco e IVEC de porta-enxertos de pessegueiro cv. Capdeboscq, submetidos a diferentes períodos de estratificação

\begin{tabular}{lcccc}
\hline \multicolumn{1}{c}{ Tratamentos } & Plântulas emergidas $(\%)$ & Altura de planta $(\mathrm{cm})$ & Diâmetro de tronco $(\mathrm{mm})$ & IVEC \\
\hline 10 dias & $67,5^{\text {ns }}$ & $69,9 \mathrm{~b}$ & $6,8^{\mathrm{ns}}$ & $12,7^{\mathrm{ns}}$ \\
40 dias & 77,5 & $73,1 \mathrm{ab}$ & 6,7 & 16,0 \\
70 dias & 76,3 & $70,0 \mathrm{~b}$ & 6,4 & 13,8 \\
100 dias & 71,3 & $76,4 \mathrm{a}$ & 6,8 & 13,8 \\
120 dias & 71,3 & $73,2 \mathrm{ab}$ & 6,9 & 14,1 \\
Médias & 72,8 & 72,5 & 6,7 & 14,1 \\
Teste F & 0,5 & 1,8 & 0,3 & 1,0 \\
C.V. $(\%)$ & 12,7 & 21,2 & 34,2 & 20,4 \\
\hline
\end{tabular}

${ }^{\text {ns }}$ não significativo; Na coluna, as médias seguidas de letras distintas, diferem entre si a $5 \%$ pelo teste de Duncan

Weekley et al., (2010) em estudo de germinação com e sem palhada como substrato para estratificação de Prunus geniculata, verificaram que com o uso de palhada, foi mantido maior umidade e consequentemente obtiveram maiores resultados de germinação de sementes. Martins, Bovi e Spiering. (2009) também verificaram melhores resultados com a cultura da pupunheira, onde avaliaram o umedecimento do substrato na emergência e vigor de plântulas e verificaram que com o uso de 60 a $90 \mathrm{~mL}$ de água em $100 \mathrm{~g}$ de substrato proporcionou máxima porcentagem de emergência das plântulas a partir dos 56 dias após a semeadura.

De acordo com os resultados encontrados por estes autores, presume-se que o frio úmido proporcionado pelas condições de campo, foi determinante para a germinação das sementes do portaenxerto cv. Capdeboscq.

Em testes alternativos de estratificação de sementes de Prunus mahaleb, Ghayyad, Kurbysa e Napolsy (2010) verificaram melhoria nos resultados relacionados à emergência com o uso alternado de frio e calor, com 4 semanas de frio, duas semanas de calor e novamente 4 semanas de frio, estes resultados foram mais eficazes do que 10 semanas contínua de estratificação a frio.

Com relação ao desenvolvimento inicial das plantas, os dados deste trabalho apresentaram um comportamento que podem estar relacionados aos fatores relatados por Wagner Junior et al. (2008b), em trabalho sobre o desenvolvimento inicial de quatro cultivares de pessegueiro. Estes autores verificaram que as diferentes cultivares apresentaram necessidades de acúmulos de frio diferentes para sua germinação, e que esse fator não interferiu durante o desenvolvimento inicial das plantas.

Para a variável dias para obtenção de até $70 \%$ de emergência de plântulas verificou-se que as sementes com menor exposição ao frio (zero e 480 horas), iniciaram a emergência após os demais tratamentos (81 dias após o plantio), enquanto que nas demais o início ocorreu aos 74 dias (Figura 1). Os $70 \%$ de emergência, conforme análise de regressão (Figura 1A, 1B, 1C e 1D) ocorreram aos $123 ; 123 ; 121$ e 112 dias após o plantio, respectivamente. Enquanto que para o tratamento com 2.640 horas de frio a porcentagem máxima obtida ao longo do período não atingiu os $70 \%$ de emergência $(67,5 \%)$. Este fato evidencia que o excesso de acúmulo de horas de frio associado com uma possível perda de umidade pode levar a redução no poder germinativo de sementes de pessegueiro da cv. Capdeboscq.

O longo período entre plantio e início de emergência de plântulas, 74 dias, pode estar associado à presença do endocarpo nas sementes, prática utilizada pela maioria dos viveiristas no Rio Grande do Sul, pois quando relacionados estes valores com os encontrados por Wagner Junior et al. (2008a) em trabalhos de germinação de seedlings de pessegueiro, sem a presença de endocarpo, estes verificaram um período inferior, entre 35 e 45 dias entre plantio e germinação e obtiveram quase que a totalidade da germinação (80\%) com no máximo de 60 dias após plantio. 
Figura 1 - Emergência de plântulas de pessegueiro cv. Capdeboscq submetidos, A - 0 h; B - 480 h; C - 1200 h; D - 1920 h e E - 2640 h de frio contínuo de $6{ }^{\circ} \mathrm{C} \pm 2{ }^{\circ} \mathrm{C} . \mathrm{F}=4,9$ e C.V. $(\%)=26,4$. ${ }^{*}$ Significante $\mathrm{p}<0,05$
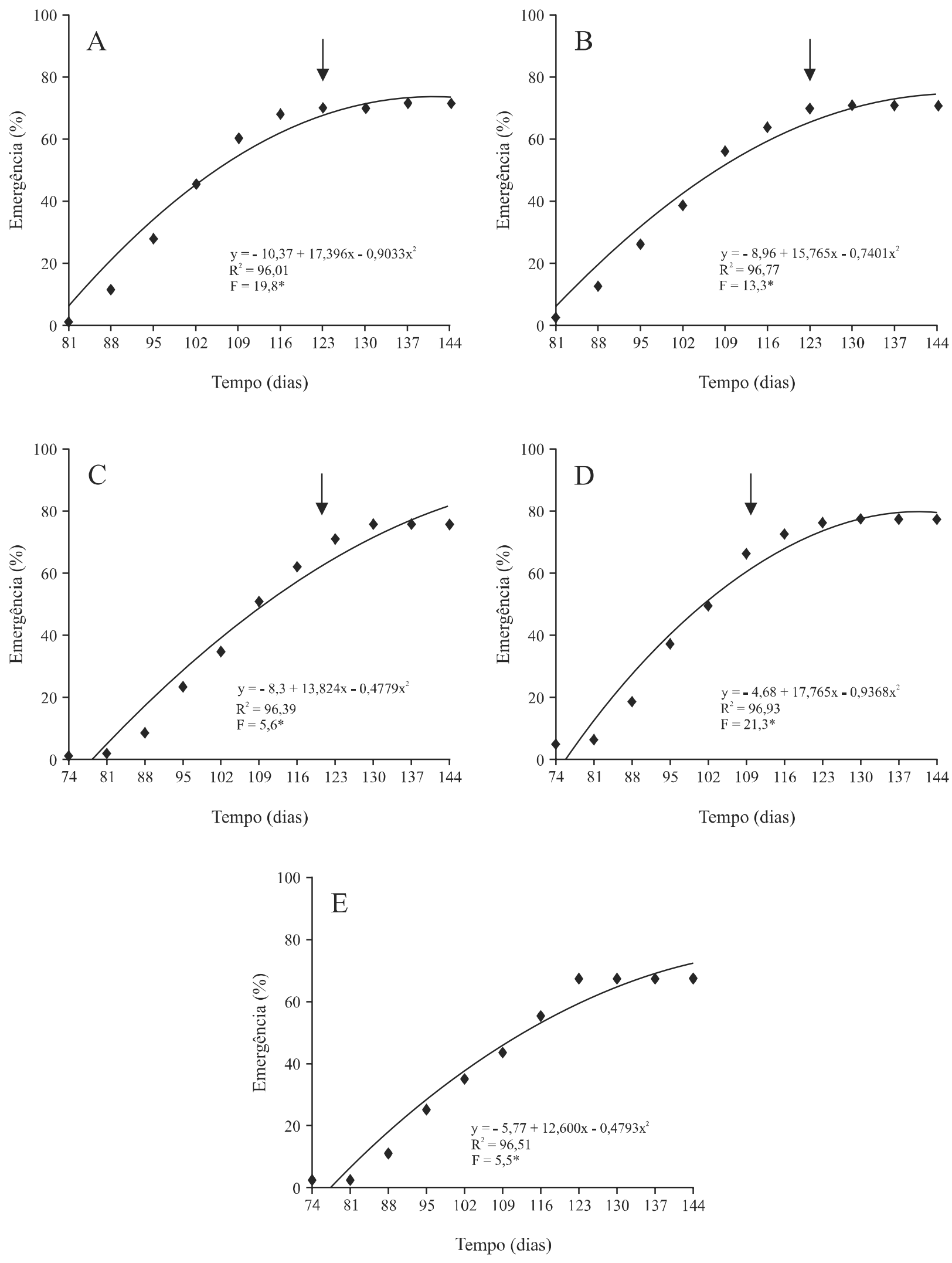


\section{CONCLUSÕES}

De acordo com dados obtidos, pode-se concluir nas condições em que foi conduzido este trabalho que:

1.Variação dos períodos de estratificação e frio, não se mostra vantajoso para obtenção de plantas de 'Okinawa' e 'Capdeboscq' como porta-enxertos de pessegueiro;

2. Sementes da cv. Okinawa com a presença do endocarpo, não se apresentam como boa alternativa para a propagação e obtenção de porta-enxerto;

3.Pode ser dispensado, para a cultivar Capdeboscq, o armazenamento a frio para a sua propagação e obtenção de novas plantas porta-enxertos de pessegueiro.

\section{AGRADECIMENTOS}

À empresa Frutplan por conceder o local e o material para a realização desta pesquisa.

\section{REFERÊNCIAS}

FACHINELLO, J. C. et al. (Ed.) Propagação de Plantas Frutíferas. Brasília: Embrapa Informação Tecnológica, 2005. cap. 3, p. 57-67.

FINARDI, N. L. Método de propagação e descrição de portaenxertos. In: MEDEIROS, C. A. B.; RASEIRA, M. do C. B. (Ed.) A cultura do pessegueiro. Pelotas: EMBRAPA/CNPAT, 1998. cap. 1, p. 100-128.

FISCHER, D. L. de O. et al. The effect of hormone, stratification period and cultivar on seeds germination of Blueberry. Acta Horticulturae, v. 872, p. 359-364, 2010.

FOOD AND AGRICULTURAL ORGANIZATION. FAOSTAT data. Disponível em: 〈http://faostat.fao.org/faostat/servlet/>. Acesso em: 28 abr. 2012.

GHAYYAD, M.; KURBYSA, M.; NAPOLSY, G. Effect of Endocarp Removal, Gibberelline, Stratification and Sulfuric Acid on Germination of Mahaleb (Prunus mahaleb L.) Seeds. American-Eurasian Journal of Agricultural \& Environmental Sciences, v. 09, n. 02, p. 163-168, 2010.
HOFFMANN, A.; NACHTIGAL, J. C.; BERNARDI, J. Sistema de produção de pêssego de mesa na região da serra gaúcha. 2003. Disponível em: <http://www. embrapa. br>. Acesso em: 10 ago. 2010.

HOFFMANN, A., FACHINELLO, J. C., NACHTIGAL, J. A. Formas de propagação por sementes. In: FACHINELLO, J. C. et al. Propagação de plantas frutíferas. Brasília, DF: Embrapa Informação Tecnológica, 2005. p. 45-67.

MACHADO, A. A.; CONCEIÇÃO, A. R. Sistema de análise estatística para windows. WinStat. Versão 2.0. Pelotas: UFPel, 2003.

MARTINS, C. C., BOVI, M. L. A., SPIERING, S. H. Umedecimento do substrato na emergência e vigor de plântulas de pupunheira. Revista Brasileira de Fruticultura, v. 31, n. 01, p. 224-230, 2009.

MAYER, N. A. et al. Distribuição do sistema radicular do pessegueiro 'Okinawa' propagado por sementes e por estacas herbáceas. Revista Brasileira de Fruticultura, v. 29, n. 03, p. 699-704, 2007.

PEREIRA, F. M.; NACHTIGAL, J. C.; ROBERTO, S. R. Tecnologia para a cultura do pessegueiro em regiões tropicais e subtropicais. Jaboticabal: FUNEP, 2002. 62 p.

RAMOS, J. D. et al. Produção de mudas de plantas frutíferas por semente. Informe Agropecuário, v. 23, n. 216, p. 64-72, 2002.

REIS, J. M. R; CHALFUN, N. N J; REIS, M. A. Estratificação, ambientes e giberilina na antecipação da enxertia do pessegueiro 'OKINAWA'. Bioscience Journal, v. 26, n. 04, p. 591-601, 2010.

WAGNER JÚNIOR, A. et al. Substratos no desenvolvimento inicial de quatro cultivares de pessegueiro e uma nectarineira. Ciência e Agrotecnologia, v. 32, n. 04, p. 1322-1328, 2008b.

WAGNER JÚNIOR, A. et al. Período de estratificação e desenvolvimento inicial de Seedlings de pessegueiro em função do número de sementes por endocarpo. Ciência e Agrotecnologia, v. 32, n. 03, p. 828-833, 2008a.

WEEKLEY, C. W. et al. E. Multiple causes of seedling rarity in scrub plum, Prunus geniculata (Rosaceae), an endangered shrub of the florida scrub. American Journal of Botany, v. 97, n. 01 , p. $144-155,2010$. 